The third interesting point is the absence of any affection of the optic nerve in the case recorded. It is noteworthy that in cases of a blow to the temple in which the optic nerve is damaged the motility of the eye is unimpaired and where a traumatic paralysis occurs the optic nerve escapes.

Yours faithfully,

EDINBURGH.

H. M. TRAQUaIR.

July $8,1947$.

\title{
COLOUR VISION IN THE CONSULTING ROOM
}

To the Editors of THE BRITISH JOURNAL OF OPHTHALMOLOGY.

DEAR SIRS.- I was pleased to see the letter from John Grieve regarding my article on colour vision, and am glad to give the explanation he requires.

The article, "Colour Vision in the Consulting Room," was a very brief résumé of some work I had done which was not published in full owing to the paper shortage, and naturally any detailed descriptions were omitted.

I made no claim that the figure of 5.5 per cent. for the gross incidence of colour defectives was anything other than the actual percentage of the subjects I had examined. These men were not chosen at random from the male population and any generalisation would have been misleading.

I consider it would have been a waste of space to describe the correct technique for using the Ishihara plates in an ophthalmological journal, and likewise considered a detailed description of the construction of the various lanterns, some of which were made from black-out shades and coffee tins, entirely irrelevant: the number and size of the apertures and the use of a rheostat appeared to be the only data necessary. The filters used approximated to those recommended by the International Committee for Aerial Navigation.

No laboratory methods could be applied to my tests, hence the title I used, and variations in colour temperature were ignored.

I hope that the résumé had made it clear that single and multilight lanterns functioned differently, the first emphasising successive contrast, the second simultaneous contrast, and/or successive, if, for the sake-of argument, one supposes that macular fixation allows only one object to be seen at a time, a point which it is not my intention to discuss.

\section{Yours truly,}

FRANK'R. NEUBERT.

HAUTERIVE,

THE QUEEN'S ROAD GUERNSEY.

July 12, 1947. 